\title{
Cerebral venous sinus thrombosis associated with COVID-19: an autopsy case report
}

\author{
Shojiro Takasu ${ }^{1} \cdot$ Mitsuko Ariizumi $^{1,2} \cdot$ Sari Matsumoto $^{1} \cdot$ Hiroshi Nakagawa $^{1} \cdot$ Kimiharu Iwadate $^{1}$
}

Accepted: 4 January 2022 / Published online: 24 January 2022

( ) The Author(s), under exclusive licence to Springer Science+Business Media, LLC, part of Springer Nature 2022

\begin{abstract}
Coronavirus disease 2019 (COVID-19) is an infectious disease caused by the SARS-CoV-2 virus. COVID-19 has been reported to increase the propensity for systemic hypercoagulability and thromboembolism disorders such as cerebral venous sinus thrombosis (CVST). A 66-year-old woman was found dead at her home. She had symptoms of fever, dizziness, and malaise 2 weeks prior to her death. However, her fever declined 3 days before death. Postmortem computed tomography conducted before the autopsy suggested CVST. On autopsy, a massive thrombus was observed from the cortical veins to the superior sagittal sinus and transverse sinus accompanied by a small infarction region in the left parietal region. Although the rapid antigen test was negative, the reverse transcription-quantitative polymerase chain reaction test was positive for SARS-CoV-2, with a cycle threshold $(\mathrm{Ct})$ value of 38.9. The serum C-reactive protein level was $0.532 \mathrm{mg} / \mathrm{dL}$. COVID-19 was the only risk factor for CVST, and no other cause of death was determined. Therefore, the cause of death was determined as acute intracranial hypertension due to CVST associated with COVID-19. The patient died after the symptoms improved, the Ct value of RT-qPCR was 38.9, and the serum C-reactive protein level decreased. Therefore, CVST might have occurred in the convalescent phase of COVID-19 infection.
\end{abstract}

Keywords COVID-19 $\cdot$ Cerebral venous sinus thrombosis $\cdot$ Postmortem CT $\cdot$ Autopsy $\cdot$ Forensic

\section{Introduction}

Coronavirus disease 2019 (COVID-19) is an infectious disease that is caused by the SARS-CoV-2 virus. An increased propensity for systemic hypercoagulability and thromboembolism has been reported among patients with COVID-19 [1-5]. Although studies have reported the manifestation of cerebral venous sinus thrombosis (CVST) in patients with COVID-19 [2-4, 6-8], the incidence of CVST is much lower $(0.02 \%)$ than that of other thromboembolic conditions such as pulmonary thromboembolism [9]. To the best of our knowledge, no autopsy reports on fatal CVST in patients with COVID-19 have been published. Here, we report a

Shojiro Takasu

s-takasu@jikei.ac.jp

1 Department of Forensic Medicine, The Jikei University School of Medicine, 3-25-8, Nishi-shinbashi, Minato-ku, Tokyo 105-8461, Japan

2 Department of Radiology, The Jikei University School of Medicine, 3-25-8, Nishi-shinbashi, Minato-ku, Tokyo 105-8461, Japan forensic autopsy case of a patient with COVID-19 related to fatal CVST.

\section{Case report}

The deceased was a 66-year-old woman who lived alone with no medical history. She was not vaccinated for SARSCoV-2 virus. She had symptoms of fever, dizziness, and malaise but did not undergo medical examination. Two weeks after the initial symptoms, she told her son, who lives separately, that her fever had declined. After 3 days, her son visited her house and found her dead in a prone position. Because the cause of death was unclear, a medicolegal autopsy was performed at our facility.

Unenhanced computed tomography (CT) was performed in the supine position using a helix 64-slice CT (Siemens Somatom go. Top CT scanner) before the autopsy. The results revealed a low-density area in the superior sagittal sinus and transverse sinus (Fig. 1). The findings in the lung showed signs of emphysema and ground-glass opacity due to postmortem hypostasis. 
Fig. 1 Postmortem computed tomography images. a Axial image of the head. Low-density area in the enlarged superior sagittal sinus (arrow). b Curved multiplanar reconstruction image of both transverse sinuses. Low-density area in both transverse sinuses are observed, especially in the left transverse sinus (arrow)
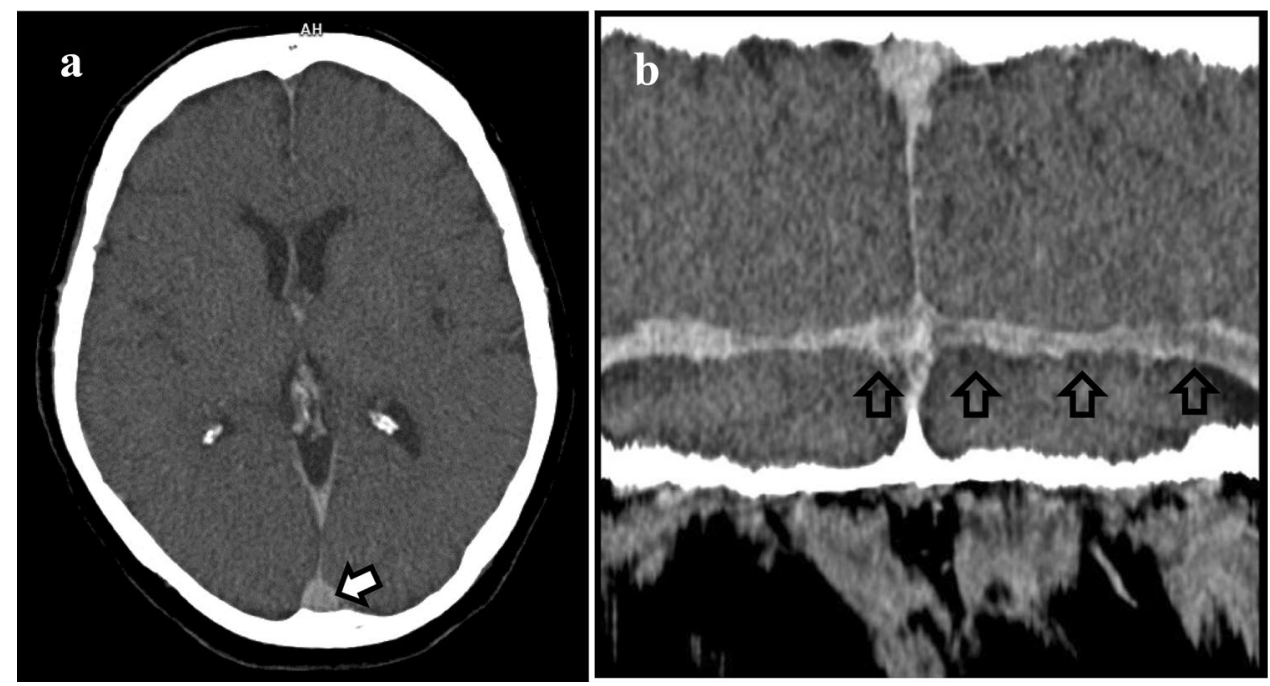

The cadaver was $157 \mathrm{~cm}$ in height and $48.3 \mathrm{~kg}$ in weight (body mass index $=19.6 \mathrm{~kg} / \mathrm{m}^{2}$ ) at the time of autopsy. Internal inspection revealed a brain weight of $1273 \mathrm{~g}$. Although no signs of edema and herniation were observed, a thrombus from the cortical veins to the superior sagittal sinus and transverse sinus was noted (Figs. 2 and 3). A small region of cerebral hemorrhagic infarction was observed in the left parietal region (Fig. 3). Histologically, lymphocytes and plasmacytes were observed in the endothelium of the left lateral sinus, and adhesion of the thrombus to the endothelium was noted (Fig. 4). The heart weighed $376 \mathrm{~g}$ and contained $230 \mathrm{~mL}$ of dark red blood with fluidity. The coronary artery showed mild-to-moderate stenosis; histologically, there was no ischemic change in the heart muscle. The left and right lungs weighed 550 and $766 \mathrm{~g}$, respectively. Although pulmonary emphysema was observed in both lungs, there was no evidence of pulmonary thromboembolism, pneumonia, and diffuse alveolar damage. No signs of macroscopic and microscopic thromboembolism were observed in the other organs. Lack of skin turgor, sunken eyes, and a dry organ surface were not observed. No signs of acute infections of the head and neck were observed. The remainder of the macroscopic and microscopic examination was unremarkable.

The nasopharyngeal swab via the nasal cavity was taken before the autopsy for the rapid antigen test and reverse transcription-quantitative polymerase chain reaction (RTqPCR) assay. Although a nasopharyngeal swab tested negative for SARS-CoV-2 via the rapid antigen test, the
Fig. 2 Cross sections of the dural sinuses. Thrombus in the superior sagittal sinus (arrow), left transverse sinus (black arrowhead), and right transverse sinus (white arrowhead) are observed

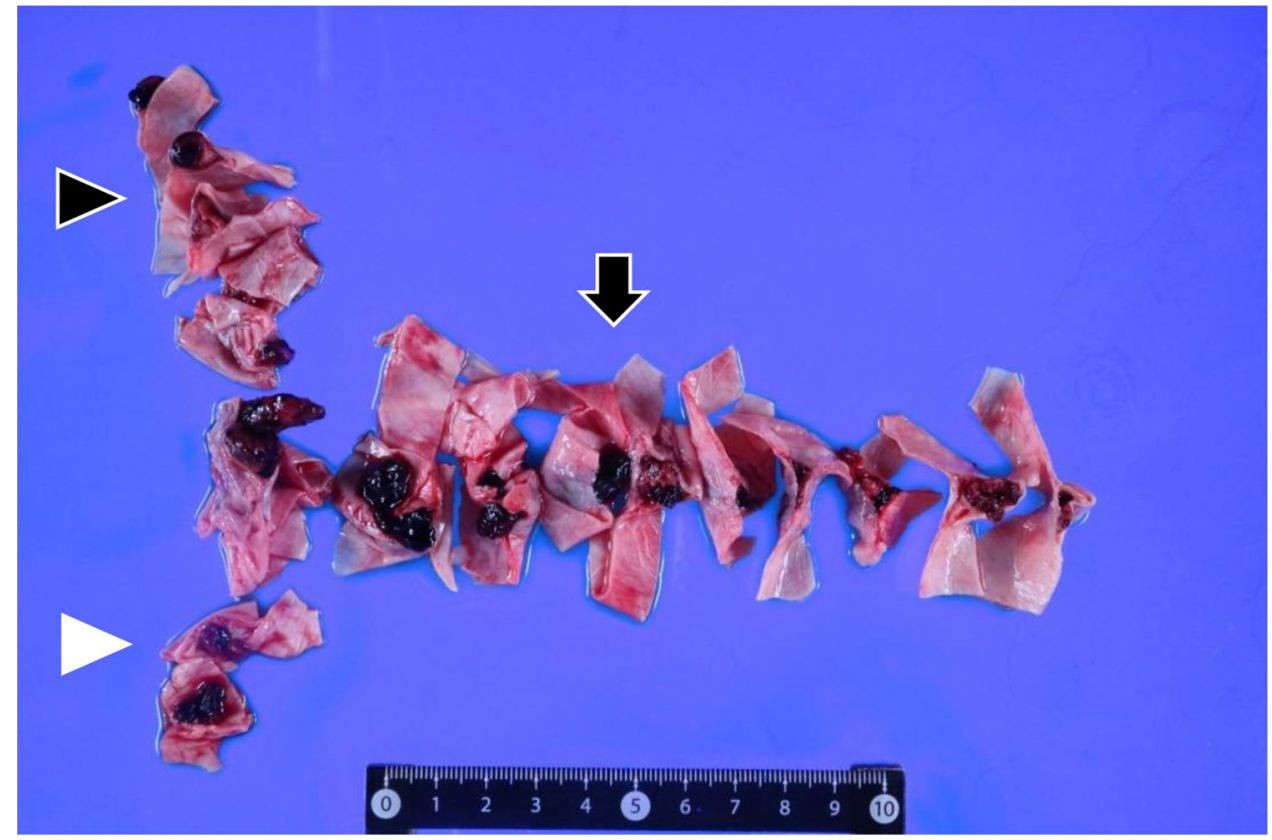




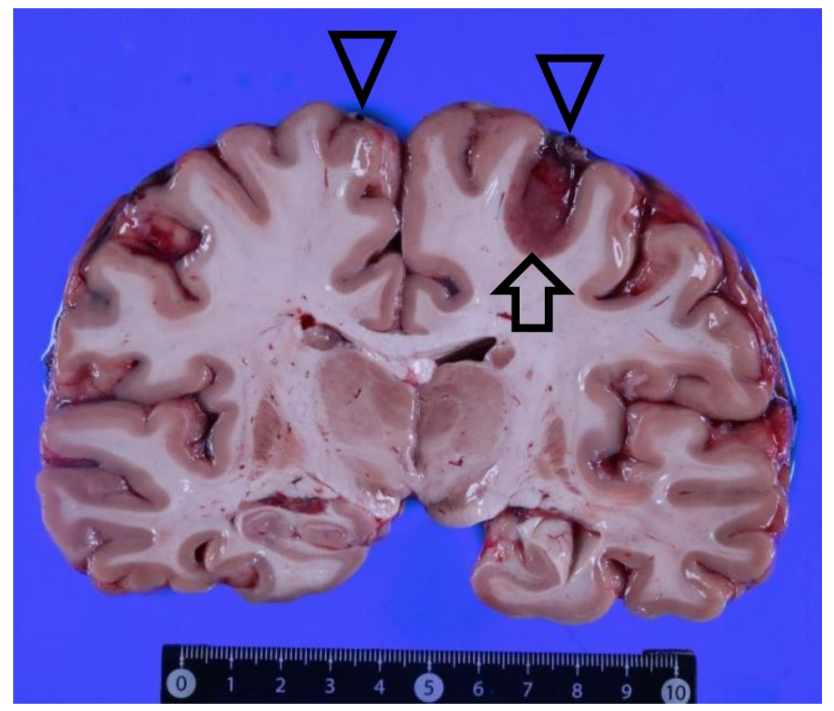

Fig. 3 Small hemorrhagic infarction in the left cortex (arrow) and thrombus in the veins of the brain convexity (arrowheads)

RT-qPCR test was positive for SARS-CoV-2, with a cycle threshold $(\mathrm{Ct})$ value of 38.9.

The serum C-reactive protein (CRP) level was $0.532 \mathrm{mg} /$ $\mathrm{dL}$, and the procalcitonin level was below the detection limit in the serum from the cardiac blood obtained at the time of autopsy. D-dimer and fibrinogen were not tested because the evidence of these measurements in postmortem specimens is scarce. No alcohol or other drugs were detected in the cardiac blood.

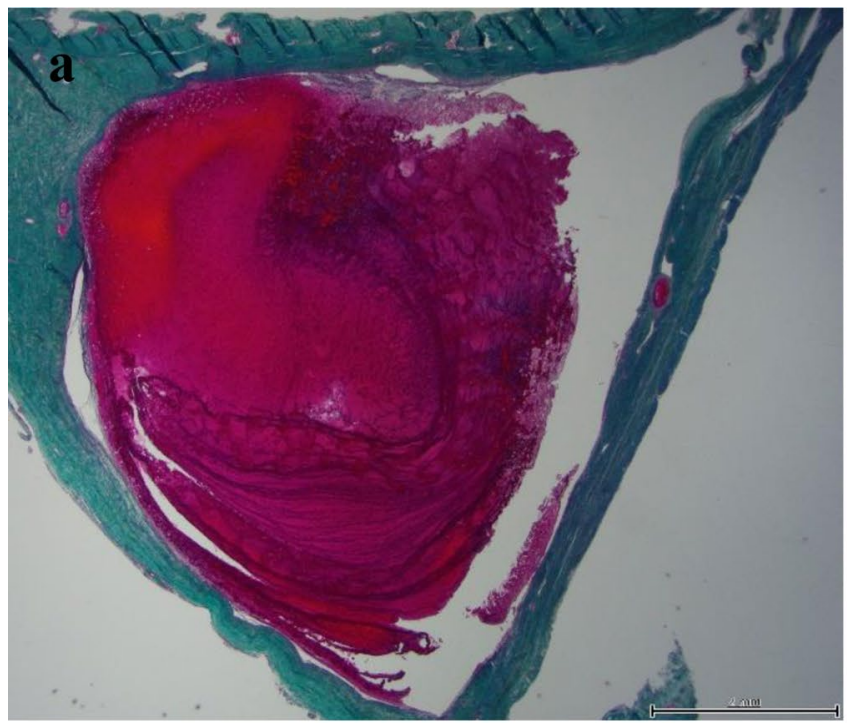

Fig. 4 Histopathology of the left transverse sinus. a Thrombus in the left transverse sinus (Elastica Masson-Goldner staining, 12.5×). b Adhesion of the endothelium of the left transverse sinus and the

\section{Discussion}

CVST is a rare condition that occurs in three to four individuals per 1 million adults and seven individuals per 1 million children in a non-COVID-19 population [10]. Although the incidence of CVST in COVID-19 patients is reported to be $0.02 \%$, it is 30-60 times greater than the incidence of CVST reported in non-COVID-19 populations [9, 10]. CVST is more common in women than in men in non-COVID-19 populations [11]. Additionally, this sex difference is reported to be similar in CVST among patients with COVID-19 [1].

The risk factors for CVST are genetic prothrombotic conditions, acquired prothrombotic states, infections, inflammatory disease, hematologic conditions, drugs (oral contraceptives and asparaginase), trauma, dehydration, and cancer [10]. In the present case, there was no history of hematological conditions and no use of prescription drugs. Moreover, no signs of cancer or dehydration were observed at the autopsy. Therefore, the cause of CVST was determined to be COVID-19. Incidentally, a study reported that $75 \%$ of patients with CVST and COVID-19 did not have identifiable risk factors for CVST [1]. Although the mechanism of venous thrombosis in patients with COVID-19 has not been completely elucidated, mechanisms such as the cytokine storm leading to endotheliitis, the contribution of angiotensinconverting enzyme 2 receptor in the endothelium of the blood vessels, and the association of antiphospholipid antibodies have been proposed [8,12-14]. In the present case, inflammatory cell infiltration was observed at the endothelium of the left transverse sinus with the adhesion

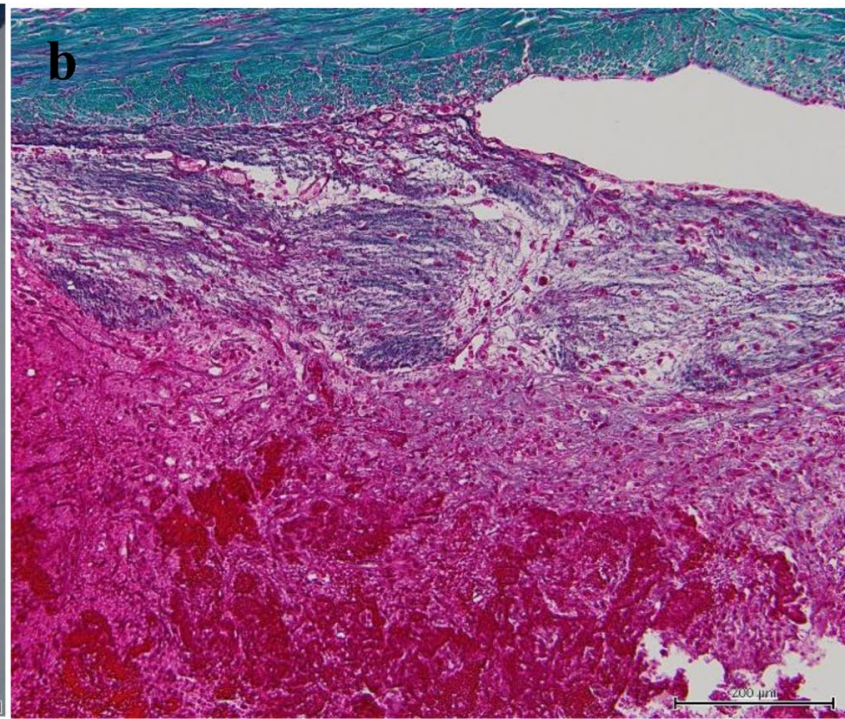

thrombus (magnification of a). Lymphocytes and plasmacytes can be observed in the endothelium (Elastica Masson-Goldner staining, $100 \times)$ 
of the thrombus. No other thrombosis was found in any other organ. Although it cannot be excluded that the inflammation of the vessel wall was secondary to the thrombus, it was suggested that endotheliitis/endothelial dysfunction was the cause of the thrombosis.

The main mechanisms of death in CVST are cerebral infarctions and hemorrhages [10]. However, an autopsy case of an individual with fatal acute intracranial hypertension caused by CVST with no signs of hemorrhage or infarction has been reported [15]. Although the present patient had a massive thrombus in the cerebral venous system, the infarct area was not sufficient to be the cause of death. Therefore, the mechanism of death was suspected to be acute intracranial hypertension.

In antemortem unenhanced CT, cerebral venous sinus appears as a low-density area compared with falx cerebri and CVST, which appear as high-density areas in the cerebral venous system [16]. However, postmortem unenhanced CT is reported to show a high attenuation in the cerebral venous sinus that is not limited to CVST [17]. Garland et al. [16] reported a postmortem CT scan of a patient with CVST, and a low-density area in the dual sinus was observed, which suggested cerebral venous sinus thrombosis. In the present case, a low-density area in the enlarged cerebral venous sinus was observed in the postmortem unenhanced CT. The low-density area was consistent with the thrombus detected in the autopsy.

Yamayoshi et al. [18] compared rapid antigen test results and RT-qPCR results and found that COVID-19 was undetectable with a rapid antigen test when the $\mathrm{Ct}$ values were $\geq 30$ in living individuals. The $\mathrm{Ct}$ value in the present case was 38.9; thus, the rapid antigen test showed a negative result, in contradiction to the RT-qPCR assay results.

The median time from the onset of COVID-19 symptoms to CVST radiological diagnosis has been reported to be 11 days (interquartile range, 6-16.75 days) [1]. Nwajei et al. [19] reported two cases in which SARS-CoV-2 testing showed negative results at the time of presentation for CVST and indicated the possibility that the prothrombotic state persists after acute infection. In the present case, the victim was found dead 2 weeks after the initial symptoms, the $\mathrm{Ct}$ value was 38.9 for the RT-qPCR result, and the CRP level was $0.532 \mathrm{mg} / \mathrm{dL}$. CRP levels in postmortem serum are reported to be stable, with the values reflecting antemortem levels [20]. Therefore, CVST might have occurred in the convalescent phase of COVID-19 infection, as previously reported.

Thrombotic incidents, including CVST, have also been reported after COVID-19 vaccination, mainly with viral vector vaccines such as the Oxford-AstraZeneca vaccine (AZD1222 (ChAdOx1)) and Johnson \& Johnson COVID19 vaccine $(\mathrm{JNJ}-78436735(\mathrm{Ad} 26 . \mathrm{COV} 2 \cdot \mathrm{S}))$ [21]. The main mechanism for vaccine-induced immune thrombotic thrombocytopenia (VITT) has been proposed to be spontaneous autoimmune heparin-induced thrombocytopenia. The incidence of VITT has been estimated to be 1 per 100,000 vaccine exposures, which is similar to the incidence of CVST in non-COVID-19 populations [22]. A study has reported that among thrombosis and thrombocytopenia syndromes associated with SARS-CoV-2 vector vaccines, the incidence and mortality rates of CVST were $51 \%$ and $38 \%$, respectively [23]. Therefore, the incidence of CVST in patients with COVID-19 is approximately 40 times greater than the incidence of CVST associated with SARS-CoV-2 vector vaccines.

To the best of our knowledge, this is the first autopsy case report of a massive fatal CVST related to COVID19. In the present case, the rapid antigen test showed a negative result at the time of autopsy. However, the RTqPCR results for COVID-19 were positive. CVST related to COVID-19 could develop in the convalescent phase of the disease. Therefore, the possibility of COVID-19 should not be excluded in cases of CVST even if the rapid antigen test is negative.

\section{Key points}

1. Cerebral venous sinus thrombosis (CVST) is a rare condition that is related to COVID-19.

2. We report an autopsy case of massive CVST revealed by postmortem computed tomography (CT) and autopsy, which was suggested to be related to COVID-19.

3. Although the nasopharyngeal swab obtained before autopsy tested negative for the rapid antigen test, the RT-qPCR test was positive for SARS-CoV-2, with a cycle threshold $(\mathrm{Ct})$ value of 38.9 .

4. Since the cerebral infarction in the present case was not fatal and no hemorrhage was observed, the cause of death was suspected to be acute intracranial hypertension caused by CVST.

5. In the present case, the test results suggested that the CVST might have occurred during the convalescent phase of COVID-19 infection.

Data availability Not applicable.

Code availability Not applicable.

\section{Declarations}

Conflict of interest The authors declare no competing interests. 


\section{References}

1. Abdalkader M, Shaikh SP, Siegler JE, Cervantes-Arslanian AM, Tiu C, Radu RA, Tiu VE, Jillella DV, Mansour OY, Vera V, Chamorro Á, Blasco J, López A, Farooqui M, Thau L, Smith A, Gutierrez SO, Nguyen TN, Jovin TG. Cerebral venous sinus thrombosis in COVID-19 patients: a multicenter study and review of literature. J Stroke Cerebrovasc Dis. 2021;30:105733. https://doi.org/10.1016/j.jstrokecerebrovasdis.2021.105733. Epub 2021 Mar 4. PMID: 33743411; PMCID: PMC7931726.

2. Hughes C, Nichols T, Pike M, Subbe C, Elghenzai S. Cerebral venous sinus thrombosis as a presentation of COVID-19. Eur J Case Rep Intern Med. 2020;7:001691. https://doi.org/10.12890/ 2020_001691. PMID: 32399457; PMCID: PMC7213833.

3. Sugiyama Y, Tsuchiya T, Tanaka R, Ouchi A, Motoyama A, Takamoto T, Hara N, Yanagawa Y. Cerebral venous thrombosis in COVID-19-associated coagulopathy: a case report. J Clin Neurosci. 2020;79:30-2. https://doi.org/10.1016/j.jocn.2020. 07.038. Epub 2020. PMID: 33070913; PMCID: PMC7377797.

4. Beretta S, Da Re F, Francioni V, Remida P, Storti B, Fumagalli L, Piatti ML, Santoro P, Cereda D, Cutellè C, Pirro F, Montisano DA, Beretta F, Pasini F, Cavallero A, Appollonio I, Ferrarese C. Case report: concomitant massive cerebral venous thrombosis and internal iliac vein thrombosis related to paucisymptomatic COVID-19 infection. Front Neurol. 2021;12: 622130. https://doi.org/10.3389/fneur.2021.622130. (PMID:3 3643200;PMCID:PMC7902908).

5. Iba T, Levy JH, Levi M, Thachil J. Coagulopathy in COVID19. J Thromb Haemost. 2020;18(9):2103-09. https://doi.org/ 10.1111/jth.14975. Epub 2020. PMID: 32558075; PMCID: PMC7323352.

6. Hemasian H, Ansari B. First case of Covid-19 presented with cerebral venous thrombosis: a rare and dreaded case. Rev Neurol (Paris). 2020;176:521-3. https://doi.org/10.1016/j.neurol. 2020.04.013. Epub 2020 May 11. PMID: 32414532; PMCID: PMC7211601.

7. Kaur I, Vyas C, Mughal M, Gandhi H, Du D. Cerebral venous sinus thrombosis in COVID-19: an unusual presentation. Cureus. 2021;13: e13767. https://doi.org/10.7759/cureus.13767. (PMID:33842143;PMCID:PMC8025961).

8. Cavalcanti DD, Raz E, Shapiro M, Dehkharghani S, Yaghi S, Lillemoe K, Nossek E, Torres J, Jain R, Riina HA, Radmanesh A, Nelson PK. Cerebral venous thrombosis associated with COVID-19. Am J Neuroradiol. 2020;41:1370-76. https://doi. org/10.3174/ajnr.A6644. Epub 2020 Jun 18. PMID: 32554424; PMCID: PMC7658892.

9. Siegler JE, Cardona P, Arenillas JF, Talavera B, Guillen AN, ChavarríaMiranda A, de Lera M, Khandelwal P, Bach I, Patel P, Singla A, Requena M, Ribo M, Jillella DV, Rangaraju S, Nogueira RG, Haussen DC, Vazquez AR, Urra X, Chamorro Á, Román LS, Thon JM, Then R, Sanborn E, de la Ossa NP, Millàn M, Ruiz IN, Mansour OY, Megahed M, Tiu C, Terecoasa EO, Radu RA, Nguyen TN, Curiale G, Kaliaev A, Czap AL, Sebaugh J, Zha AM, Liebeskind DS, Ortega-Gutierrez S, Farooqui M, Hassan AE, Preston L, Patterson MS, Bushnaq S, Zaidat O, Jovin TG. Cerebrovascular events and outcomes in hospitalized patients with COVID-19: the SVIN COVID-19 multinational registry. Int J Stroke. 2020:1747493020959216. https://doi.org/10. 1177/1747493020959216. Epub ahead of print. PMID: 32852257; PMCID: PMC7533468.

10. Stam J. Thrombosis of the cerebral veins and sinuses. N Engl J Med. 2005;352(17):1791-8. https://doi.org/10.1056/NEJMra042354. (PMID: 15858188).

11. Alvis-Miranda HR, Milena Castellar-Leones S, Alcala-Cerra G, Rafael M-S. Cerebral sinus venous thrombosis. J Neurosci
Rural Pract. 2013;4:427-38. https://doi.org/10.4103/0976-3147. 120236. (PMID:24347950;PMCID:PMC3858762).

12. Zhang Y, Xiao M, Zhang S, Xia P, Cao W, Jiang W, Chen H, Ding $\mathrm{X}$, Zhao H, Zhang H, Wang C, Zhao J, Sun X, Tian R, Wu W, Wu D, Ma J, Chen Y, Zhang D, Xie J, Yan X, Zhou X, Liu Z, Wang J, Du B, Qin Y, Gao P, Qin X, Xu Y, Zhang W, Li T, Zhang F, Zhao Y, Li Y, Zhang S. Coagulopathy and antiphospholipid antibodies in patients with Covid-19. N Engl J Med. 2020;382(17):e38. https://doi.org/10.1056/NEJMc2007575. Epub 2020 Apr 8. PMID: 32268022; PMCID: PMC7161262.

13. Connors JM, Levy JH. COVID-19 and its implications for thrombosis and anticoagulation. Blood. 2020;135:2033-40. https:// doi.org/10.1182/blood.2020006000. (PMID:32339221;PMCID: PMC7273827).

14. Varga Z, Flammer AJ, Steiger P, Haberecker M, Andermatt R, Zinkernagel AS, Mehra MR, Schuepbach RA, Ruschitzka F, Moch H. Endothelial cell infection and endotheliitis in COVID19. Lancet. 2020;395(10234):1417-8. https://doi.org/10.1016/ S0140-6736(20)30937-5. Epub 2020 Apr 21. PMID: 32325026; PMCID: PMC7172722.

15. De-Giorgio F, Peschillo S, Vetrugno G, d'Aloja E, Spagnolo AG, Miscusi M. Cerebral venous sinus thrombosis due to spontaneous, progressive, and retrograde jugular vein thrombosis causing sudden death in a young woman. Forensic Sci Med Pathol. 2015;11:88-91. https://doi.org/10.1007/s12024-014-9633-9. (Epub 2014 Dec 21 PMID: 25527307).

16. Garland J, Kesha K, Vertes D, Modahl L, Milne D, Ruder T, Stables S, Tse R. Empty delta sign on unenhanced postmortem computed tomography scan in cerebral venous thrombosis. Am J Forensic Med Pathol. 2018;39:360-3. https://doi.org/10.1097/ PAF.0000000000000421. (PMID: 30024432).

17. Smith AB, Lattin GE Jr, Berran P, Harcke HT. Common and expected postmortem CT observations involving the brain: mimics of antemortem pathology. Am J Neuroradiol. 2012;33:1387-91. https://doi.org/10.3174/ajnr.A2966. Epub 2012 Apr 5. PMID: 22492568 ; PMCID: PMC7965507.

18. Yamayoshi S, Sakai-Tagawa Y, Koga M, Akasaka O, Nakachi I, Koh H, Maeda K, Adachi E, Saito M, Nagai H, Ikeuchi K, Ogura T, Baba R, Fujita K, Fukui T, Ito F, Hattori SI, Yamamoto K, Nakamoto T, Furusawa Y, Yasuhara A, Ujie M, Yamada S, Ito M, Mitsuya H, Omagari N, Yotsuyanagi H, Iwatsuki-Horimoto K, Imai M, Kawaoka Y. Comparison of rapid antigen tests for COVID-19. Viruses. 2020;12:1420. https://doi.org/10.3390/v12121420. (PMI D:33322035;PMCID:PMC7764512).

19. Nwajei F, Anand P, Abdalkader M, Andreu Arasa VC, Aparicio HJ, Behbahani S, Curiale G, Daneshmand A, Dasenbrock H, Mayo T, Mian A, Nguyen T, Ong C, Romero JR, Sakai O, Takahashi C, Cervantes-Arslanian AM. Cerebral venous sinus thromboses in patients with SARS-CoV-2 infection: three cases and a review of the literature. J Stroke Cerebrovasc Dis. 2020;29:105412. https:// doi.org/10.1016/j.jstrokecerebrovasdis.2020.105412. Epub 2020 Oct 19. PMID: 33254367; PMCID: PMC7571902.

20. Takasu S, Matsumoto S, Kodama S, Sakamoto K, Iwadate K. Comparison of C-reactive protein levels between antemortem serum and postmortem serum and pericardial fluid. J Forensic Leg Med. 2020;73: 101968. https://doi.org/10.1016/j.jflm.2020. 101968. (Epub 2020 May 12 PMID: 32442115).

21. Sharifian-Dorche M, Bahmanyar M, Sharifian-Dorche A, Mohammadi P, Nomovi M, Mowla A. Vaccine-induced immune thrombotic thrombocytopenia and cerebral venous sinus thrombosis post COVID-19 vaccination; a systematic review. J Neurol Sci. 2021;428:117607. https://doi.org/10.1016/j.jns.2021.117607. Epub 2021 Aug 3. PMID: 34365148; PMCID: PMC8330139.

22. Cines DB, Bussel JB. SARS-CoV-2 Vaccine-induced immune thrombotic thrombocytopenia. N Engl J Med. 2021;384(23):2254-6. 
https://doi.org/10.1056/NEJMe2106315. Epub 2021 Apr 16. Erratum in: N Engl J Med. 2021;384(23):e92. PMID: 33861524; PMCID: PMC8063912.

23. Palaiodimou L, Stefanou MI, Katsanos AH, Aguiar de Sousa D, Coutinho JM, Lagiou P, Michopoulos I, Naska A, Giannopoulos S, Vadikolias K, Voumvourakis KI, Papaevangelou V, Vassilakopoulos TI, Tsiodras S, Tsivgoulis G. Cerebral venous sinus thrombosis and thrombotic events after vector-based COVID-19 vaccines: a systematic review and meta-analysis. Neurology. 2021;97(21):e2136-47. https://doi.org/10.1212/WNL.0000000000012896. Epub 2021 Oct 5. PMID: 34610990.

Publisher's Note Springer Nature remains neutral with regard to jurisdictional claims in published maps and institutional affiliations. 